\title{
Selective impairment of facial recognition due to a haematoma restricted to the right fusiform and lateral occipital region
}

\author{
Y Wada, T Yamamoto
}

\begin{abstract}
A 67 year old right handed Japanese man developed prosopagnosia caused by a haemorrhage. His only deficit was the inability to perceive and discriminate unfamiliar faces, and to recognise familiar faces. He did not show deficits in visual or visuospatial perception of non-facial stimuli, alexia, visual agnosia, or topographical disorientation. Brain MRI showed a haematoma limited to the right fusiform and the lateral occipital region. Single photon emission computed tomography confirmed that there was no decreased blood flow in the opposite left cerebral hemisphere. The present case indicates that a well placed small right fusiform gyrus and the adjacent area can cause isolated impairment of facial recognition. As far as we know, there has been no published case that has demonstrated this exact lesion site, which was indicated by recent functional MRI studies as the most critical area in facial recognition. (F Neurol Neurosurg Psychiatry 2001;71:254-257)
\end{abstract}

Keywords: prosopagnosia; magnetic resonance imaging; single photon emission computed tomography; right fusiform gyrus

Prosopagnosia is a unique syndrome in which recognition of familiar faces is impaired. Recent reports have found it to occur in patients with lesions confined to the right temporo-occipital region. ${ }^{1}$ As the restricted unilateral lesion in most of these previous cases were demonstrated by CT, it is possible that other lesions existed that might have escaped visualisation. Few cases of prosopagnosia have been reported in which the lesions were confined to the right hemisphere by MRI, SPECT, or PET. ${ }^{12}$ However, these cases exhibited visually related dysfunction as well as prosopagnosia, such as topographical disorientation, alexia, and visual object agnosia. So there remains an uncertainty as to the critical lesion responsible for prosopagnosia. We herein report a case of the selective impairment of face recognition after a haemorrhage confined to the right fugiform and lateral occipital region, confirmed by MRI.
Case report

The patient was a 67 year old, right handed, retired journalist with a history of non-systemic vasculitic polyneuropathy 3 years previously. He experienced a sudden disturbance of the visual field and became aware of his inability to recognise the faces of family members and even thought that his own reflection in the mirror was the face of a stranger. Two days later, when he came to our hospital, he was unable to recognise his doctor, but knew him by his voice. At that time, brain CT disclosed a haemorrhage in the inferolateral part of the right occipital lobe.

He was alert and oriented. He initially had a mild left homonymous hemianopia that vanished within 2 weeks (Goldmann visual field was normal). Visual acuity was $1.0(20 / 20)$ in both eyes. Colour vision was intact with Ishihara colour plates (no achromatopsia). Ocular movements were full. The remaining cranial nerves were intact. He had remaining bilateral sensory deficit and muscle weakness in the distal parts of his four limbs due to nonsystemic vasculitic polyneuropathy. No dysmetria was found. Tendon reflexes were absent and Babinski's sign was negative on both sides.

$\mathrm{He}$ could no longer recognise his wife or other familial people when he saw their faces. He said that he would usually identify family members and friends by non-facial, distinguishing features. He was also unable to recognise photographed faces of famous people. For example, confronted with a photograph of the Japanese sumo champion, Akebono, in front of the Meiji shrine, he could not recognise his face, but immediately named the shrine correctly.

During 3 months after the onset, the degree of his impairment in face recognition remained so severe as to interfere with daily life. Thereafter his symptoms improved to some extent, but he still reported that he was often unable to recognise the faces of famous people photographed in the newspaper. We followed him up for more than 6 months and his symptoms still remained.

\section{BRAIN IMAGING}

Brain MRI was carried out 27 days after onset. The lesion involved the right inferior occipital region at the level of the fusiform gyrus, and inferior and fourth occipital gyri, but spared 


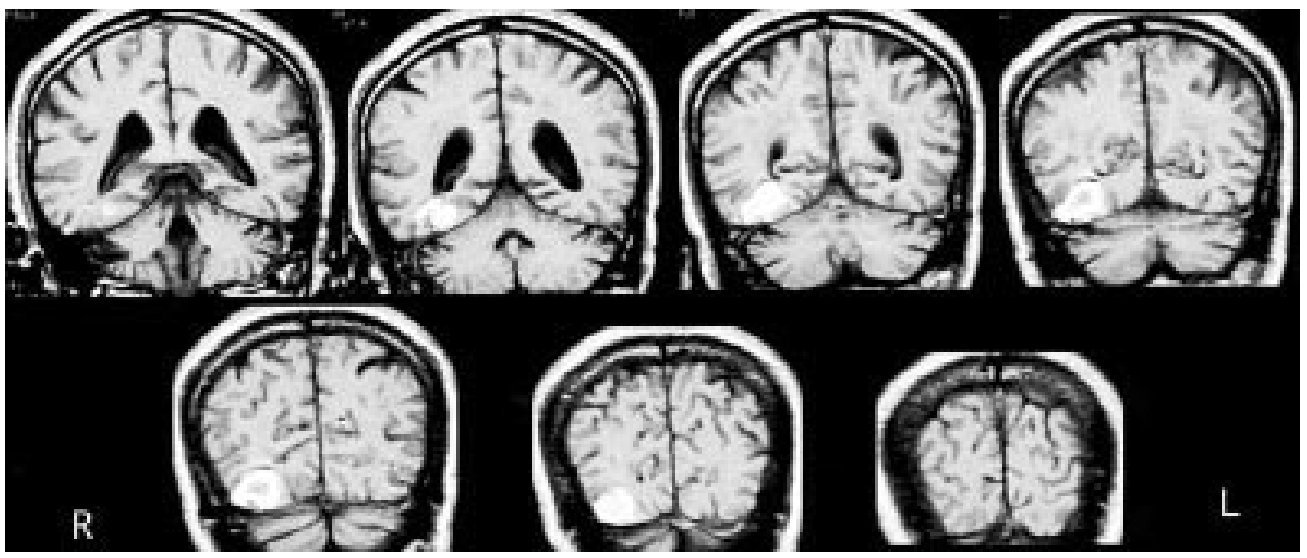

Figure 1 Coronal view of the T1 weighted MR images $(T M / T E=300 / 4.2)$. The images show a high intensity area in the right fusiform gyrus and lateral occipital region.

Table 1 Patient's performance on tests

\begin{tabular}{|c|c|c|}
\hline Assessment & Score & Normal subjects (mean (SD)) \\
\hline \multicolumn{3}{|l|}{ VPTA (visual perception test for agnosia) } \\
\hline \multicolumn{3}{|l|}{ Visual perception: } \\
\hline Distinguishing the length of line & 0 & $0.0(0.00)$ \\
\hline Counting dots & 0 & $0.0(0.00)$ \\
\hline Distinguishing the shape & 0 & $0.3(0.80)$ \\
\hline Line orientation & 0 & $0.1(0.64)$ \\
\hline Perception of overlapping figures & 0 & $0.1(0.40)$ \\
\hline Picture copying test & 0 & $0.3(0.72)$ \\
\hline \multicolumn{3}{|l|}{ Recognition of picture and real object: } \\
\hline Picture naming & 0 & $0.0(0.14)$ \\
\hline Real object naming & 0 & $0.0(0.00)$ \\
\hline Story telling (the cookie theft picture) & 0 & $1.1(1.96)$ \\
\hline \multicolumn{3}{|l|}{ Colour perception: } \\
\hline Naming & 0 & $0.4(1.24)$ \\
\hline Pointing & 0 & $0.1(0.72)$ \\
\hline Matching & 0 & $0.0(0.38)$ \\
\hline Sorting & 0 & \\
\hline Visual memory for object's colour & 0 & \\
\hline Matching to objects given verbally & 0 & $0.1(0.35)$ \\
\hline Matching to pictures of objects & 0 & $0.1(0.48)$ \\
\hline \multicolumn{3}{|l|}{ Recognition of letters and symbols: } \\
\hline Recognition of symbols & 0 & $0.83(1.61)$ \\
\hline Recognition of letters (kanji) & 0 & $0.1(0.44)$ \\
\hline Recognition of letters (kana) & 0 & $0.0(0.27)$ \\
\hline Recognition of numbers & 0 & $0.58(2.18)$ \\
\hline \multicolumn{3}{|l|}{ Visual space perception tests: } \\
\hline Line bisection test & 0 & $0.1(0.49)$ \\
\hline Line cancellation test & 0 & $0.0(0.30)$ \\
\hline Picture copying test & 0 & $0.1(0.58)$ \\
\hline Drawing the clock & 0 & \\
\hline Drawing the man's face & 0 & $0.1(0.46)$ \\
\hline \multicolumn{3}{|l|}{ Topographic orientation: } \\
\hline Recall of the location of familiar buildings & 0 & \\
\hline Geographical knowledge & 0 & \\
\hline \multicolumn{3}{|l|}{ Face tests: } \\
\hline Famous people's face recognition & 11 & $0.8(1.95)$ \\
\hline Unknown face matching & 4 & $0.6(1.12)$ \\
\hline Simultaneous identification & 3 & $0.1(0.27)$ \\
\hline Perception of expression & 0 & $0.0(0.14)$ \\
\hline Perception of sex & 6 & \\
\hline Perception of age & 7 & \\
\hline \multicolumn{3}{|l|}{ Other tests } \\
\hline \multicolumn{3}{|l|}{ Line drawing: } \\
\hline Naming & 86 & $86(0.6)$ \\
\hline Recognition & 90 & $87(0.3)$ \\
\hline \multicolumn{3}{|l|}{ Picture naming: } \\
\hline Conventional views & $10 / 10$ & \\
\hline Unconventional views & $10 / 10$ & \\
\hline \multicolumn{3}{|l|}{ Famous places: } \\
\hline Naming & $6 / 6$ & \\
\hline Recognition & $6 / 6$ & \\
\hline Animal face naming: & $6 / 6$ & \\
\hline \multicolumn{3}{|l|}{ Tests of unfamiliar faces } \\
\hline Face matching (different angle) & $12 / 14$ & $12.9(1.9)$ \\
\hline Learning unknown faces & $10 / 18$ & $13.0(2.7)$ \\
\hline \multicolumn{3}{|l|}{ Familiar face recognition: } \\
\hline Identification of familiar faces & $2 / 11$ & \\
\hline Familiarity check & $1 / 9$ & \\
\hline Famous face identification & $8 / 38$ & $35.7(3.6)$ \\
\hline Familiarity check & $1 / 30$ & \\
\hline Identification from name & $38 / 38$ & \\
\hline
\end{tabular}

^Blank indicates that these tests are not normalised; bold=impaired performance. the striate, lingual cortices, and parahippocampal gyrus (fig 1). N-isopropyl- $\left({ }^{123} \mathrm{I}\right)-\mathrm{p}$ iodoamphetamine SPECT disclosed decreased blood flow corresponding to the haemorrhage.

GENERAL COGNITIVE FUNCTIONING

$\mathrm{He}$ was alert and fully oriented to time and space, obtaining a score of $30 / 30$ on the mini mental state examination. There was no personal change or apparent intellectual deterioration. No deficit of language or praxis was seen. ${ }^{3}$ He scored 32/36 on the Raven coloured progressive matrice (normal range). He had no memory impairment and his memory index on the Wechsler memory scale-revised (WMS-R) were normal (general memory index 96; visual memory index 104; verbal memory index 91 ; delayed memory index 91). Reading ability was also intact.

\section{EXPERIMENTAL INVESTIGATIONS}

Visual perception tests

He never complained of difficulty in recognising objects and places, or finding his way around places. General visual perception and visual construction were tested using the visual perception test for agnosia (VPTA), ${ }^{4}$ which is a test standardised in Japan, designed to assess higher order visual perceptual abilities. As shown in table 1, in VPTA, he performed at a normal level in all categories except for the face recognition task. He showed various deficits in the face recognition task except for perception of expression task.

In addition to VPTA, his visual performance was assessed with a battery of tests of increasing difficulty. The detail of methods and items are listed in the appendix.

\section{Methods}

VISUAL PERCEPTION TESTS EXCEPT VPTA

(1) Naming and recognition of line drawings; we used the method of Kazui et al. ${ }^{5}$

(2) Picture naming (conventional and unconventional views); the photographs of 10 common objects were used.

(3) Naming and recognition of famous places; 12 photographs were used.

(4) Naming of animal faces; the photographs of six animals were used. 
(5) Face matching.

(6) Memory of faces; for (5) and (6) (appendix) we used the method of Kazui et al. ${ }^{5}$

(7) Identification of familiar faces: a series of nine photographs were used.

(8) Famous face identification; the photographs of 38 famous faces were used.

(9) Identification from name; we investigated whether he had an intact knowledge of famous people.

\section{Results}

As shown in table 1, he responded correctly on visual perception tests and thus, there was no evidence of any significant decline in visuoperceptual abilities. By contrast, he showed various deficits in tests of face processing. In the face matching test, his performance was slow but within the normal range. In the memory faces test, he showed a mild deficit. In the familiar faces identification test, he was able to identify only two out of 11 faces, and for most of the rest he responded that he had no idea. Of nine faces that he could not identify, he reported that only one face was encountered before. It was noted that he could neither identify nor had familiarity with his own face. In famous faces identification, he showed a severe deficit. By contrast, by identification from name, he was able to provide detailed information correctly.

\section{Discussion}

After extensive testing, our patient was found to manifest impairment restricted to the recognition of faces, due to the small lesion in the right fusiform and lateral occipital region. $\mathrm{He}$ demonstrated severe prosopagnosia, yet he showed no clear deficit in visual or visuospatial perception of non-facial stimuli. He showed no other abnormal findings that could possibly cause a disturbance of face recognition, such as dementia or general memory disturbance. $\mathrm{He}$ could also recognise common visual objects shown from both canonical and non-canonical perspectives on photographs. So far in the literature, all prosopagnosic patients who had been subjected to a detailed examination had displayed visual perceptual deficits of nonfacial stimuli. Landis et al reported a prosopagnosic patient who was the first patient studied postmortem. ${ }^{6}$ They also reported that their patient was unable to identify the items when presented non-canonically. Sergent and Signoret also reported on three prosopagnosic patients who were all unable to recognise objects seen from a non-canoninal perspective. ${ }^{7}$ However, Warrington and Taylor had already pointed out that this deficit was typically associated with the right inferior parietal lesion. ${ }^{8}$ Similarly to our patient, patient OR reported by De Renzi et $a l^{1}$ scored normally on tests for the objects presented from atypical views. Thus these findings provide evidence that prosopagnosia and deficits in recognising objects shown from unconventional views are distinct signs and the last is not necessarily associated with prosopagnosia.

Our patient was impaired in the task of learning unknown faces despite normal visual memory. Our data were in agreement with the contention of Takahashi et al that the impairment in the ability to memorise new faces was a common feature of prosopagnosia. However, their patients were impaired on Benton's visual retention test. This dissociation in our patient's visual memory emphasised that the impairment of our patient was face specific.

Our search in the literature over the past 25 years has shown that there were only nine prosopagnosic patients so far, whose damage was confined to the right hemisphere as shown by MRI, and 10 patients by PET. ${ }^{1}{ }^{2}$ The lesion in our patient was localised in the right fusiform, inferior, and fourth occipital gyri. Takahashi et $a l^{9}$ suggested that the cortical/subcortical damage to the lingual and fusiform gyri play the most important part in prosopagnosia. However, similarly to our patient, the lingual cortex was spared in patient PC reported on by Sergent and Signoret. ${ }^{7}$ We think, therefore, that the fusiform gyrus is mainly involved in the recognition of the face.

Recent investigations of face perception in normal subjects using functional imaging techniques identified the right fusiform gyrus, and proposed that this region is primarily involved in face perception. ${ }^{10-14}$ Our present finding is consistent with these functional imaging results.

We are very grateful to Dr Y Eguchi, at the Graduate School of Human and Environmental Studies, Kyoto University, for the generous gift of material of tests, and thank Dr Yasushi Kita, and Hisako Saida, STR, at the Department of Neurology, Osaka Saiseikai Nakatsu Hospital.

\section{Appendix: Lists of methods and items} used in the tests of visual perception and Investigation of face processing.

(1) NAMING AND RECOGNITION OF LINE

DRAWINGS

The test stimuli were the 90 line drawings from Kazui et $a l^{5}$ which consisted of nine diverse categories (vehicles, musical instruments, animals, processed food, utensils, vegetables/ fruits, sports, body parts, and colours). Each picture was presented, one at a time, with the instructions to name each object as it was presented. He was later given a recognition test, usually during a separate session. In this case each of the stimulus pictures was presented along with nine others drawn from the same category. Instructions were simply to point to the picture named. Recognition was tested for all pictures regardless whether or not he had been correctly named in the earlier session.

(2) PICTURE NAMING (CONVENTIONAL AND UNCONVENTIONAL VIEW)

Photographs of 10 common objects taken both from a conventional and an unconventional view were presented for naming, following the procedure devised by Wallington and Taylor. ${ }^{10}$ Unconventional views were given first.

\section{(3) NAMING AND RECOGNITION OF FAMOUS} PLACES

He was shown a set of photographs of 12 famous Japanese places including famous sites and historical monuments (for example, 
Mount Fuji, Kiyomizu temple) and asked to provide the name or as much identifying information as possible. On another occasion he was provided with the name of each place and asked to provide as much information about it as possible.

(4) NAMING OF ANIMAL FACES

The photographs of the head regions of six well known animals were shown to the patient, and he was asked to provide the name or as much identifying information as possible.

(5) FACE MATCHING

We used the method of Kazui et $a l^{5}$, constructed in analogy with the test of Benton and Van Allen. ${ }^{15}$ A total of 21 photographs of Japanese were prepared, seven being frontal views, seven three quarter views, and seven lateral views. He was requested to match these faces with those of other views.

(6) MEMORY OF FACES

Following the method of Kazui et al, ${ }^{5}$ the ability to recognise faces (including hair) was tested with 18 photographs of Japanese women. Firstly, photographs of nine women were shown and then he was asked to recognise them from the full set of 18 photographs, presented after a delay of 15 minutes.

(7) IDENTIFICATION OF FAMILIAR FACES

He was shown a series of nine photographs of the patient himself and doctors or hospital staff who have been familiar with him for more than 2 years, as well as two photographs of the doctor and nurse whom he had often seen subsequent to the onset of haemorrhage. $\mathrm{He}$ was asked to identify these faces. If unable to name the person, he was asked to provide as much identifying information as he could. The score used here was the number of faces he could name or provide sufficient information to uniquely identify the person. If unable to identify them, he was asked to make a yes/no judgement as to whether or not he thought the face was encountered previously.

(8) FAMOUS FACE IDENTIFICATION

He was shown 38 famous faces (including 25 politicians) selected from a remote memory test, using the stimuli of Eguchi et al from the 1970s-90s. ${ }^{16}$ The procedure of this test was the same as that for identification in the familiar face test.

(9) IDENTIFICATION FROM NAME

We investigated whether he had intact knowledge of people by giving him the name of the 38 famous people whose photographs were used in the famous face identification test. $\mathrm{He}$ was asked to provide as much information as possible.

1 De Renzi E, Perani D, Carlesimo GA, et al. Prosopagnosia can be associated with damage confined to their right hemisphere-a MRI and PET study and a review of the lithemisphere-a MRI and PET study and a

2 Tohgi H, Watanabe K, Takahashi H, et al. Prosopagnosia without topographagnosia and object agnosia associated with a lesion confined to the right occipitotemporal region. F Neurol 1994;241:470-4

3 Wada Y, Nakagawa Y, Nishikawa T, et al. Role of somatosensory feedback from tools in realizing movements by patients with ideomotor apraxia. Eur Neurol 1999;41: $73-8$.

4 The Committee for the Visual Perception Test, Japanese Society of Aphasiology. Visual perception tests for agnosia: VPTA. Tokyo: Shinko Igaku Shuppansha, 1997. (In VPTA. To

5 Kazui H, Tanabe H, Ikeda M, et al. A case of predominantly right-temporal lobe atrophy with disturbance of identifying familiar faces. Brain and Nerve (Tokyo) 1995;47:77-85. (In Japanese.)

6 Landis T, Regard M, Bliestle A, et al. Prosopagnosia and agnosia for non-canonical views. An autopsy case. Brain 1988;111:1287-97.

7 Segent J, Signoret JL. Varieties of functional deficits in prosopagnosia. Cerebral Cortex 1992;2:375-88.

8 Warrington EK, Taylor AM. The contribution of the right parietal lobe to object recognition. Cortex 1973;9:152-64.

9 Takahashi N, Kawamura M, Hirayama K, et al. Prosopagnosia: a clinical and anatomical study of four patients. Cortex 1995;31:317-29.

10 Sergent J, Ohta S, MacDonald B, et al. Functional neuroanatomy of face and object processing. A positron emission tomography study. Brain 1992;115:15-36.

11 Haxby JV, Horwitz B, Ungerleider LG, et al. The functional organization of human extrastriate cortex: a PET-rCBF study of selective attention to faces and locations. 7 Neurosci 1994;14:6336-53.

12 Puce A, Allison T, Gore JC, et al. Face-sensitive regions in human extrastriate cortex studied by functional MRI. $\mathfrak{F}$ heurophysiol 1995;74:1192-9.

13 Kanwisher N, McDermott J, Chun MM. The fusiform face area: a module in human extrastriate cortex specialized for face perception. F Neurosci 1997;17:4302-11.

14 Nakamura K, Kawashima R, Sato N, et al. Functional delineation of the human occipito-temporal areas related to face and scene processing. A PET study. Brain 2000;123: 1903-12.

15 Benton AL, Van Allen NW. Impairment in facial recognition in patients with cerebral disease. Cortex 1968;4:344-58.

16 Eguchi Y, Kazui H, Nagano K, et al. A new test of remote memory using visual stimuli and its application to amnesic two patients. $7 p n \mathcal{F}$ Neuropsychol 1996;12:58-66. (In Japanese.) 